\title{
A literature review and systematic meta-analysis on XRCC3 Thr241Met polymorphism associating with susceptibility of oral cancer
}

\author{
JIANLIN FAN ${ }^{1 *}$, WEI LIU ${ }^{2 *}$, MINGZHI ZHANG ${ }^{3}$ and CHUNGEN XING ${ }^{4}$ \\ ${ }^{1}$ Department of Stomatology, The Second Affiliated Hospital of Soochow University, Suzhou, Jiangsu 215004; \\ ${ }^{2}$ Department of Pathology, The First Affiliated Hospital of Soochow University, Suzhou, Jiangsu 215006; \\ ${ }^{3}$ Department of Epidemiology, School of Public Health, Medical College of Soochow University, Suzhou, Jiangsu 215123; \\ ${ }^{4}$ Department of General Surgery, The Second Affiliated Hospital of Soochow University, Suzhou, Jiangsu 215004, P.R. China
}

Received December 11, 2018; Accepted June 21, 2019

DOI: 10.3892/ol.2019.10609

\begin{abstract}
Oral cancer is very common, occurring on head as well as neck region with poor prognosis. The X-ray repair cross-complementing group 3 (XRCC3) gene contained in DNA repairing pathway has been investigated for its functional role in oral cancer. Nevertheless, the corresponding results are inconclusive. This study investigated the association of XRCC3 Thr241Met polymorphism regarding oral cancer risk. Article and literature searches were performed using Embase, Medline, PubMed, Wanfang and China National Knowledge Infrastructure (CNKI) databases with a manual search. The keywords of ' $X R C C 3$ or $\mathrm{X}$-ray repair cross complementing protein 3', 'polymorphism or SNP', 'oral cancer or oral squamous cell carcinoma' and their combinations were used to search literature. In accordance with the criteria of inclusion, we focused on only case-and-control studies with the distribution of genotypes and alleles being available to be extracted. Systematic meta-analysis was conducted via the STATA software (version 11.0). After a comprehensive literature collection and review, 1,615 oral cancer cases and 1,897 matched controls extracted from 7 articles were included for this meta-analysis.
\end{abstract}

Correspondence to: Dr Chungen Xing, Department of General Surgery, The Second Affiliated Hospital of Soochow University, 1055 Sanxiang Road, Suzhou, Jiangsu 215004, P.R. China

E-mail: xigbdm9837@163.com

*Contributed equally

Abbreviations: $X R C C 3, \mathrm{X}$-ray repair cross complementing group 3; SNPs, Single-nucleotide polymorphisms; CNKI, China National Knowledge Infrastructure; OSCC, oral squamous cell carcinoma; OR, odds ratio; CI, confidence interval; PCR-RFLP, polymerase chain reaction restriction fragment length polymorphism; HRR, homologous recombination repair; HWE, Hardy-Weinberg equilibrium; BER, base excision repair

Key words: polymorphism, meta-analysis, XRCC3 gene, oral cancer
Our results show that only Met/Met (TT) genotype with the recessive model was associated with high risk of oral cancer $(\mathrm{CC}+\mathrm{CT}$ vs. TT, $\mathrm{OR}=1.81, \mathrm{P}=0.001,95 \% \mathrm{CI}=1.28-2.567) . \mathrm{A}$ significant relationship was identified under both homozygous and recessive model in Asians (CC vs. TT: $\mathrm{OR}=2.15,95 \%$ $\mathrm{CI}=1.107-4.170, \mathrm{P}=0.024 ; \mathrm{CT}+\mathrm{CC}$ vs. $\mathrm{TT}: \mathrm{OR}=2.140,95 \%$ $\mathrm{CI}=1.105-4.144, \mathrm{P}=0.024)$, but not among Caucasians $(\mathrm{P}>0.05)$. The results indicate that XRCC3 241Met allele might be a potential factor for oral cancer risk, particularly among Asian population. A further study using a larger population and more ethnicities should be performed to confirm the findings.

\section{Introduction}

Oral cancer is one of the most common cancers in the head as well as neck region, and is a major public health issue worldwide. It develops on the tongue, lips, gum, salivary glands, buccal mucosa, palate, and even the floor of mouth. There were 300,000 estimated new cases in 2012 worldwide, with two thirds developing in men (1). Although oral cancer is ranked as the 15th most common cancer, it is often not diagnosed until a very advanced stage and the lethality of $50 \%$ has caused much concern (1). Moreover, recent data suggested that the incidence of oral cancer has highly increased in the last two decades $(2,3)$. The vast majority of oral cancer is derived from the multi-layered squamous epithelium and is referred to as oral squamous cell carcinoma (OSCC). Three major lifestyle factors, namely areca nut chewing, alcohol consumption, and smoking are generally considered as main causative factors for oral cancer. Genetic confounders, however, are of great interest but remain unclear.

Polymorphisms are prevalent genetic loci, which play a vital role during the process of human traits. Single-nucleotide polymorphisms (SNPs) are low penetrate genetic variants, which are found to be associated with cancer susceptibility (4). DNA repair genes prevent the genome from being damaged, which are due to endogenic or environmental carcinogens. The defect in DNA repair system is proved to induce pre-cancerous lesions and cancers (5). In this regard, it is natural to make the hypothesis that part of the genetic variants with DNA repairing genes may influence the DNA repair ability and infer 


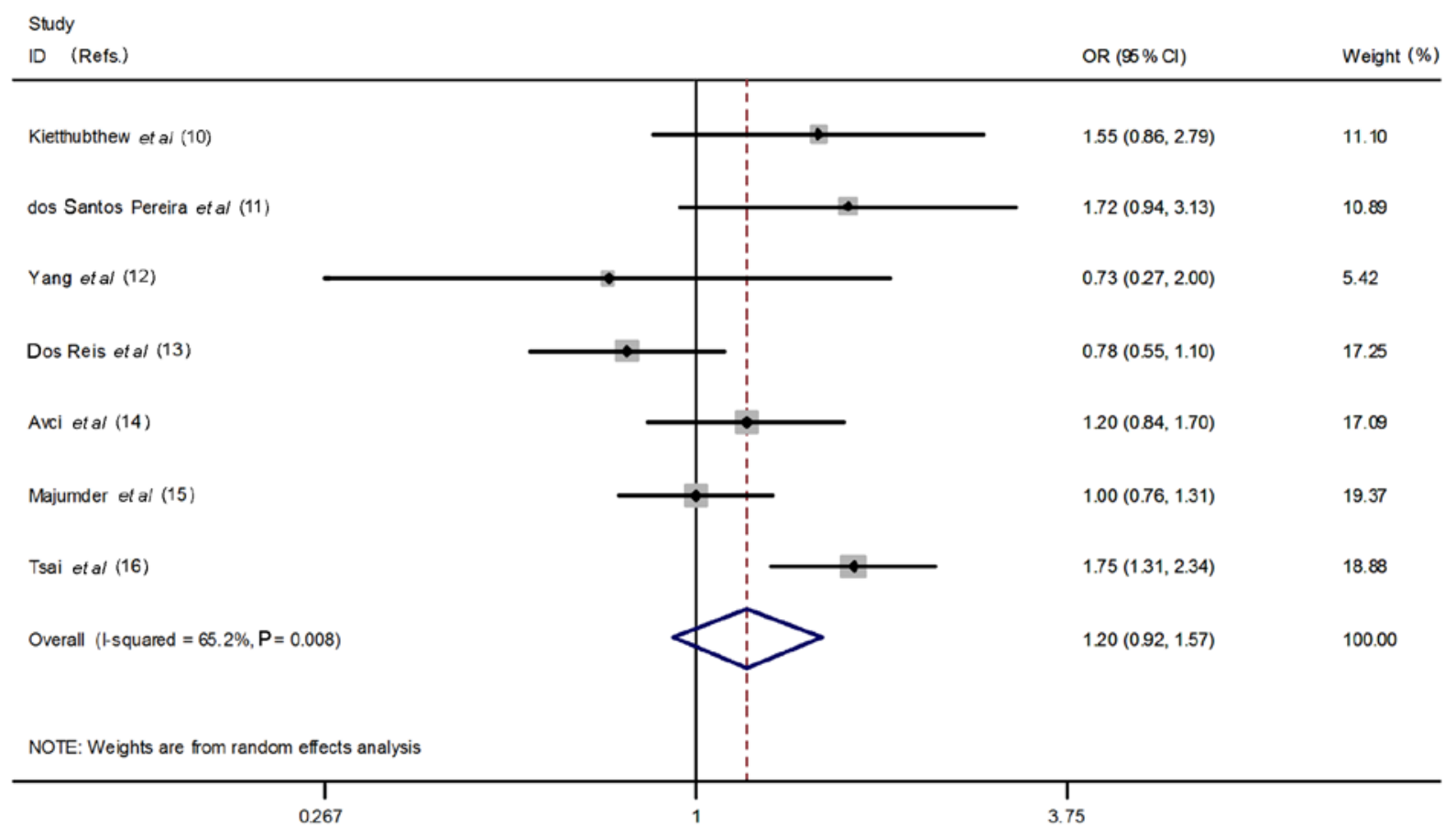

Figure 1. Meta-analysis on the correlation regarding XRCC3 Thr241Met polymorphism to oral cancer risk using the allele model (C vs. T). XRCC3, X-ray repair cross complementing group 3.

susceptibility of oral cancer. X-ray repair cross-complementing group 3 (XRCC3), located mainly on chromosome 14q32.3, belongs to the RAD51 family. It has been proven to participate in double strand break and homologous recombination repair (6). It is one of the most important genes related to DNA repair. The Thr241Met (18607C/T, rs861539) polymorphism, a $\mathrm{C} / \mathrm{T}$ substitution in exon seven, has resulted in a Thr-to-Met amino-acid alteration. It has drawn wide attention as its variant influences repair capacity for DNA damage, and has been confirmed to be related to increased risk of various cancers (7-9). Moreover, previous research has investigated the association regarding Thr241Met polymorphism to the risk of oral cancer. However, the data are inconclusive (10-16). For example, the $241 \mathrm{Met}$ allele showed a $>3$-fold increased risk for oral cancer in Thai population (10), while no significant association was identified in Brazilian patients (13). This discrepancy may be due to various aspects. From a statistical perspective, studies with relatively inadequate sample sizes have low power to identify low penetric genetic variants. On the other hand, the lack of reproducibility might also be due to discrepant genetic or lifestyle backgrounds. To solve the inconsistence of previous studies and verify the association of XRCC 3 Thr241Met polymorphisms and oral cancer risk meta-analysis was conducted using the most recent published datasets.

\section{Materials and methods}

Search strategy for identification of associated studies. An extensive literature review was conducted by using Embase, Medline, PubMed, Wanfang and CNKI online resources. Related papers published from January 2000 to September 2017 were selected. In order to include both English and Chinese-language articles, the keywords ' $\mathrm{XRCC} 3$ or X-ray repair cross-complementing protein 3', 'polymorphism or SNP', 'oral cancer or oral squamous cell carcinoma' and their combinations were utilized as well as the relevant Chinese characters were chosen in searches of the Chinese database. To filter and include more related articles, bibliography listed in the retrieved papers was manually searched. If there were multiple articles from the same authors or research groups, the most recent data or the largest datasets were included.

Inclusion and exclusion criteria. All the selected studies had to be covered by the following inclusion criteria: caseand-control studies that focused on the association study of XRCC3 Thr241Met polymorphisms regarding oral cancer risk. Distribution of genotypes and allele information of patients or controls were accessible, or with the odds ratio (OR) with its $95 \%$ confidence intervals (CIs). The criteria of exclusion included: review articles or abstracts from conferences; studies without control group or data were not available to be extracted.

The study was approved by the Ethics Committee of the Second Affiliated Hospital of Soochow University (Suzhou, China). Patients or their guardians signed an informed consent.

Statistical analysis. In the present meta-analysis, XRCC3 Thr241Met polymorphism between patients and controls was compared by the unadjusted ORs and 95\% CIs. Significance of the pooled ORs is indicated and tested via Z-test. The Mantel-Haenszel model using the $\chi^{2}$ test was performed to estimate heterogeneity between different groups. The following five genetic models were performed to assess the association between the Thr241Met polymorphism and oral cancer: allele model (Met vs. Thr), homozygous model (Met/Met vs. Thr/Thr), dominant model(Met/Met+Thr/Met vs.Thr/Thr), heterozygous model (Met/Thr vs. Thr/Thr) and recessive model (Met/Met vs.Thr/Met + Thr/Thr). Between-study heterogeneity 
Table I. Main characteristics of included studies in this meta-analysis.

\begin{tabular}{|c|c|c|c|c|c|c|c|c|c|c|c|c|c|c|c|c|}
\hline \multirow{3}{*}{$\begin{array}{l}\text { First } \\
\text { authors (Refs.) }\end{array}$} & \multirow[b]{3}{*}{ Year } & \multirow[b]{3}{*}{ Country } & \multicolumn{12}{|c|}{ Genotype and allele information } & \multirow[b]{3}{*}{ HWE } & \multirow{3}{*}{$\begin{array}{l}\text { Gentotyping } \\
\text { methods }\end{array}$} \\
\hline & & & \multicolumn{2}{|c|}{ Sample size } & \multicolumn{5}{|c|}{ Cases } & \multicolumn{5}{|c|}{ Controls } & & \\
\hline & & & Cases & Controls & s CC & $\mathrm{CT}$ & TT & $\mathrm{C}$ & $\mathrm{T}$ & $\mathrm{CC}$ & $\mathrm{CT}$ & TT & $\mathrm{C}$ & $\mathrm{T}$ & & \\
\hline Avci et al (14) & 2017 & Turkey & 111 & 148 & 34 & 25 & 52 & 93 & 129 & 28 & 81 & 39 & 137 & 159 & 0.22 & PCR-RFLP \\
\hline Kietthubthew et al (10) & 2006 & Thailand & 106 & 164 & 83 & 22 & 1 & 188 & 24 & 140 & 23 & 1 & 303 & 25 & 0.96 & PCR-RFLP \\
\hline Majumder et al (15) & 2005 & India & 310 & 348 & 201 & 97 & 12 & 499 & 121 & 220 & 120 & 8 & 560 & 136 & 0.07 & PCR-RFLP \\
\hline Dos Reis et al (13) & 2012 & Brazil & 144 & 144 & 63 & 72 & 9 & 198 & 90 & 52 & 78 & 14 & 182 & 106 & 0.05 & PCR-RFLP \\
\hline dos Santos Pereira et al (11) & 2015 & Brazil & 53 & 39 & 10 & 34 & 9 & 54 & 52 & 15 & 20 & 4 & 50 & 28 & 0.48 & PCR-RFLP \\
\hline Tsai et al (16) & 2014 & China & 788 & 956 & 684 & 92 & 12 & 1460 & 116 & 878 & 73 & 5 & 1829 & 83 & 0.01 & PCR-RFLP \\
\hline Yang et al (12) & 2015 & China & 103 & 98 & 96 & 7 & 0 & 199 & 7 & 89 & 9 & 0 & 187 & 9 & 0.63 & PCR-RFLP \\
\hline
\end{tabular}

HWE, the Hardy-Weinberg equilibrium. PCR-RFLP, polymerase chain reaction restriction fragment length polymorphism.

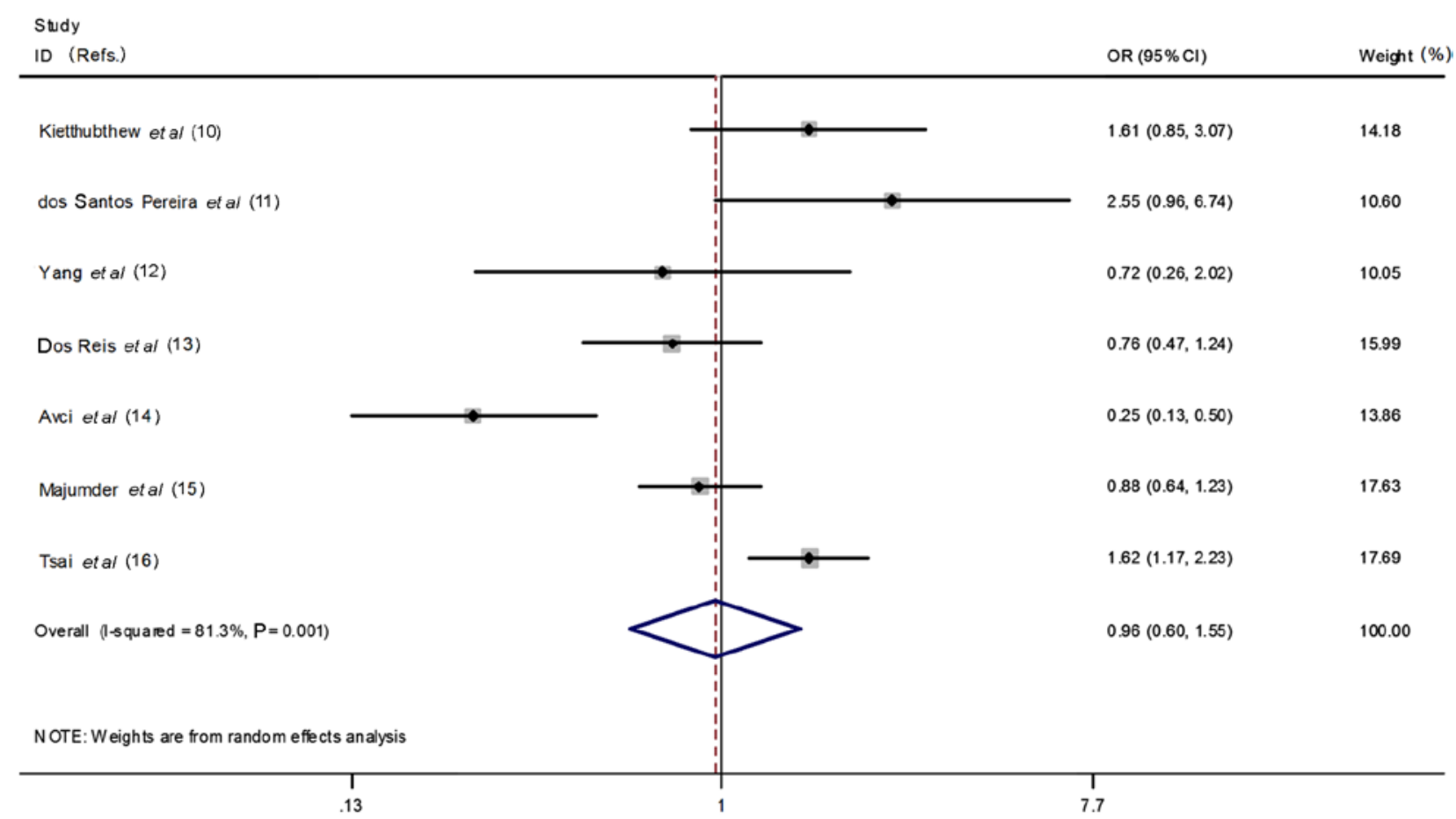

Figure 2. Meta-analysis on the correlation regarding XRCC3 Thr241Met polymorphism to oral cancer risk using heterozygous model (CT vs.CC). XRCC3, $\mathrm{X}$-ray repair cross complementing group 3 .

was captured by the inconsistency index $\mathrm{I}^{2}$ test along with the statistic Q-test. Fixed effect model was employed in case of homologous effects $\left(\mathrm{P}>0.01\right.$ and $\left.\mathrm{I}^{2}<50 \%\right)$. Random-effect model was utilized when the effects were heterogeneous $\left(\mathrm{P}<0.01\right.$ and $\left.\mathrm{I}^{2}>50 \%\right)$. Egger regression asymmetry test and funnel plots were utilized to validate publication bias. Probability $\leq 0.05$ was considered as significant with the exception of the $\mathrm{I}^{2}$ statistic and Egger's test, when a significant level of $<0.1$ was applied. STATA version 11.0 for Windows was used for statistical analyses and data management.

Data extraction and quality assessment. Two independent investigators performed extraction of data. Disagreements were solved by adjustments of the third investigator through achieving a consensus. The following information was included: year of publication, the first author, sample size, country, genotyping methods, ethnicity, the Hardy-Weinberg equilibrium (HWE) in controls, and allele and genotype distribution.

\section{Results}

Study identification and inclusion. In summary, 15 relevant studies were kept after the above-mentioned searches. Using the inclusion and exclusion criteria, finally 7 studies were selected, which include 1,615 oral cancer cases and 1,897 related controls. The 7 articles were from studies of five countries and regions, mainly involving two ethnicities (3 groups of Caucasians and 4 groups of Asians). Sample sizes 


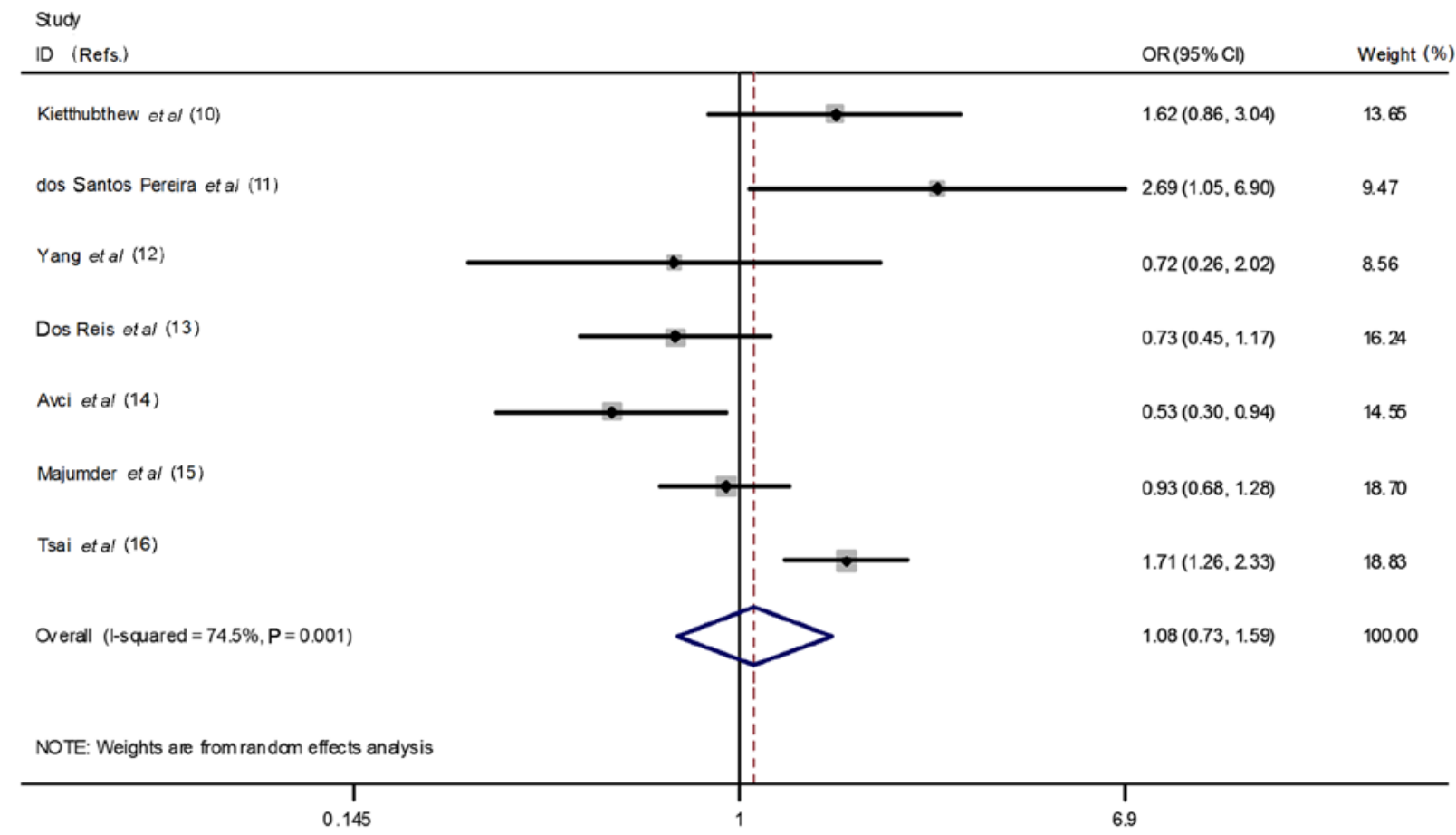

Figure 3. Meta-analysis on the correlation regarding XRCC3 Thr241Met polymorphism to oral cancer risk by the dominant model (CT + TT vs. CC). XRCC3, X-ray repair cross complementing group 3.

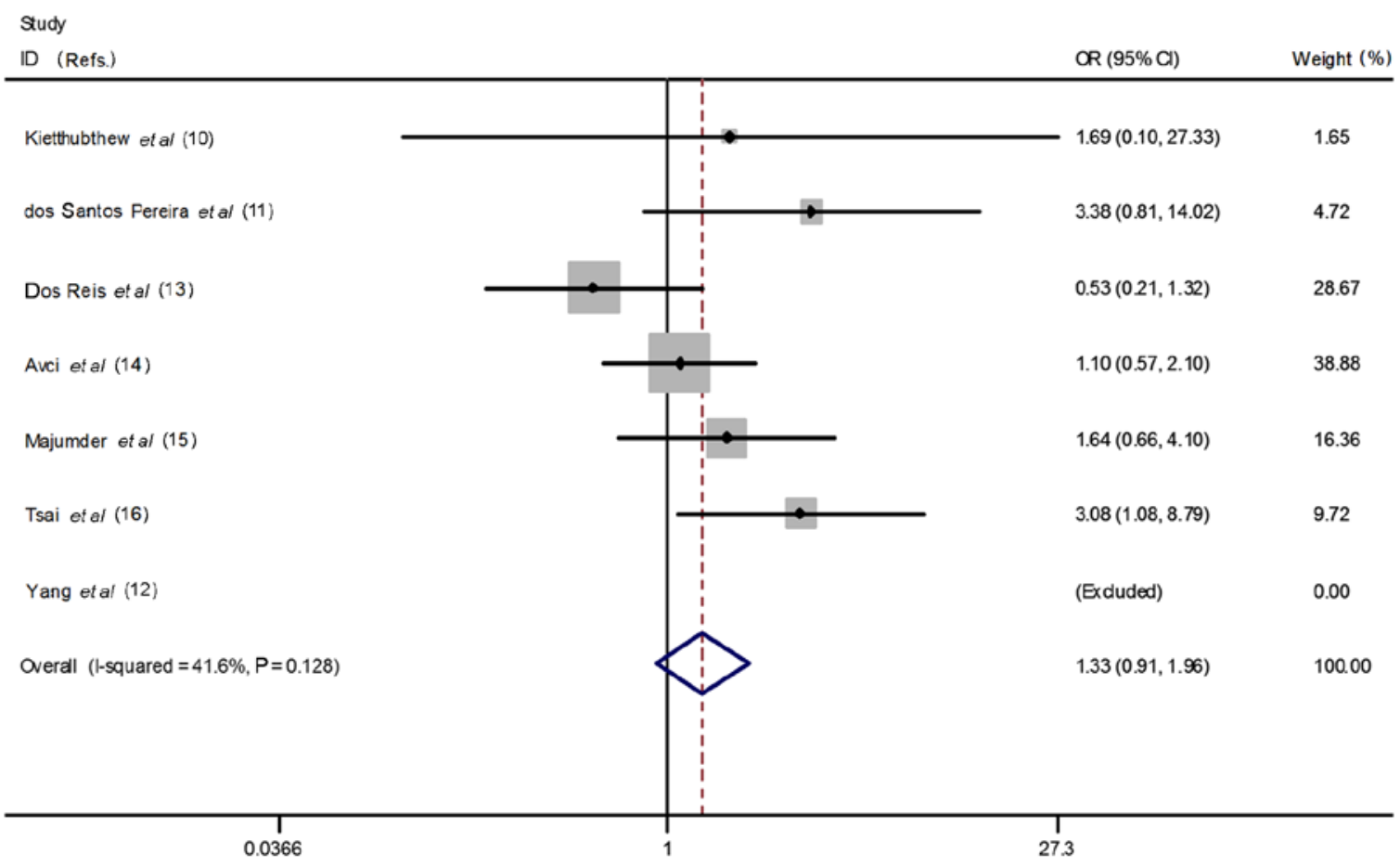

Figure 4. Meta-analysis on the correlation regarding XRCC3 Thr241Met polymorphism to oral cancer risk by the homozygous model (TT vs.CC). XRCC3, $\mathrm{X}$-ray repair cross complementing group 3.

of the data ranged from 92 to 1744 . Polymerase chain reaction restriction fragment length polymorphism (PCR-RFLP) method was applied for SNP genotype. Detailed information is provided in Table $\mathrm{I}$.

Association of XRCC3 Thr241Met SNP regarding overall oral cancer risk. There are seven articles that contain
1,615 oral cancer patients and 1,897 controls. Heterogeneity of the involved literature was analyzed. The fixed effect and random effect models were respectively utilized. Despite the fact that $\mathrm{T}$ allele frequency is rather high in patients comparing with controls $(16.7 \%$ vs. $14.4 \%)$, our analyses did not infer a significant association between the $\mathrm{T}$ allele and oral cancer susceptibility ( $\mathrm{T}$ vs. $\mathrm{C}$ : $\mathrm{OR}=1.20$, 


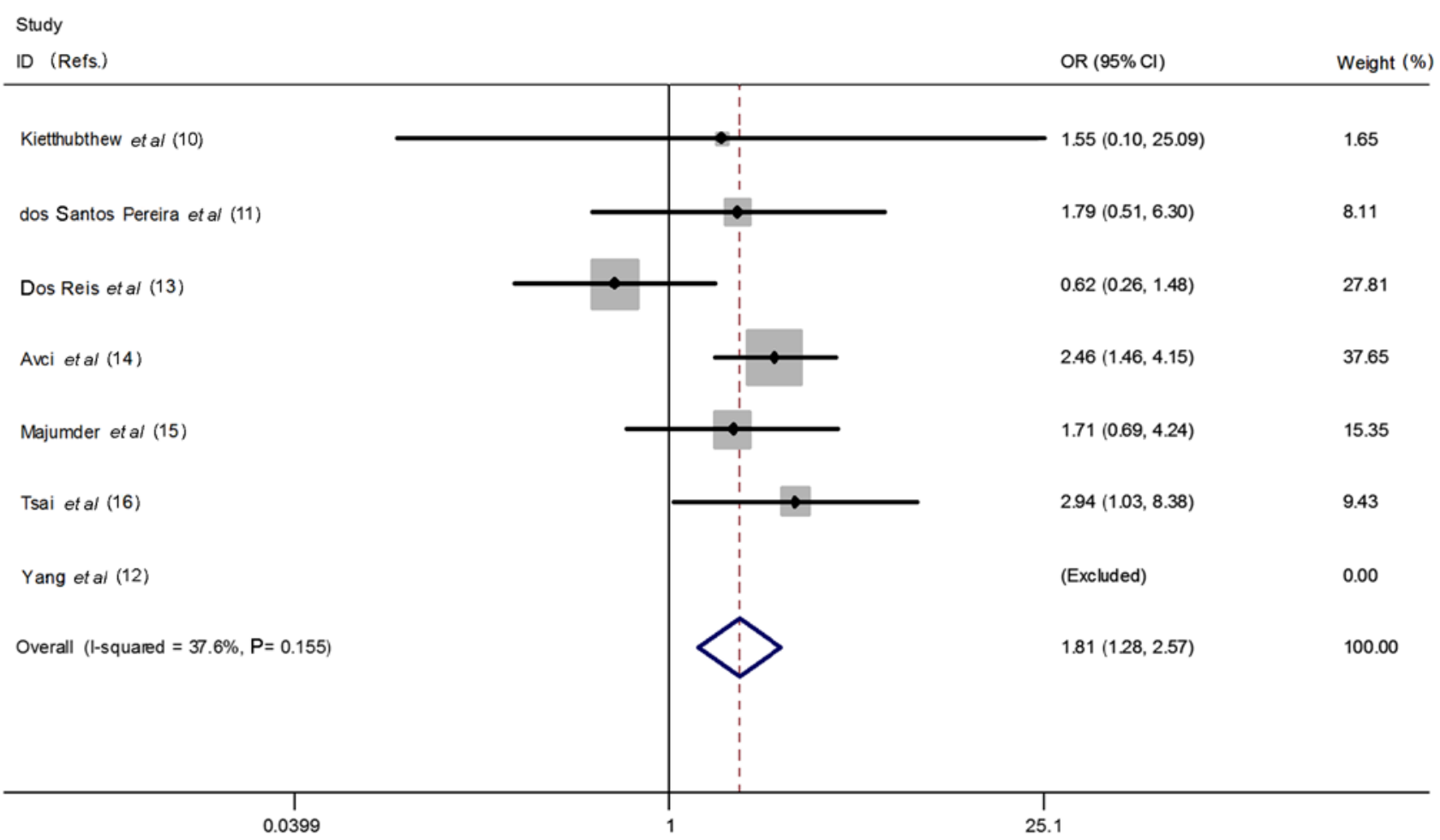

Figure 5. Meta-analysis on the correlation regarding XRCC3 Thr241Met polymorphism to oral cancer risk under recessive model (TT versus CC $+\mathrm{CT}$ ) $X R C C 3, \mathrm{X}$-ray repair cross complementing group 3.

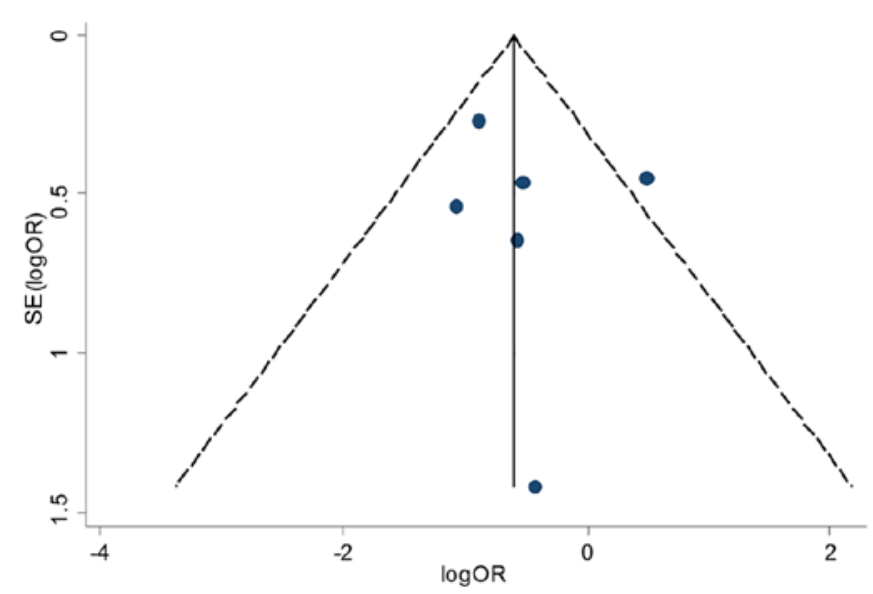

Figure 6. Funnel plots on publication bias for the associations between XRCC3 Thr241Met polymorphism and susceptibility to oral cancer through the allele model. $X R C C 3, \mathrm{X}$-ray repair cross complementing group 3; SE, standard error; OR, odds ratio.

95\% $\mathrm{CI}=0.92-1.57, \mathrm{P}=0.18)$ by applying the random effect model (Fig. 1). Neither was significance identified by using heterozygous model (CT vs. $\mathrm{CC}$ : $\mathrm{OR}=0.96,95 \% \mathrm{CI}=0.60-1.55$, heterogeneity $\mathrm{P}=0.001, \mathrm{I}^{2}=81.3 \%$, Fig. 2), dominant model (CT + TT vs. CC: $\mathrm{OR}=1.08,95 \% \mathrm{CI}=0.73-1.59$, heterogeneity $\mathrm{P}=0.001, \mathrm{I}^{2}=74.5 \%$, Fig. 3 ); homozygous model (CC vs. TT: $\mathrm{OR}=1.33,95 \% \mathrm{CI}=0.91-1.96$, heterogeneity $\mathrm{P}=0.13, \mathrm{I}^{2}=41.6 \%$, Fig. 4); However, as shown in Fig. 5, a significant relationship was identified for the recessive model. TT genotype was positively associated with oral cancer risk (TT vs. CT + CC: $\mathrm{OR}=1.81, \mathrm{P}=0.001,95 \% \mathrm{CI}=1.28-2.57$, heterogeneity $\mathrm{P}=0.155$, $\mathrm{I}^{2}=37.6 \%$.
Table II. Association of areca nut chewing, XRCC 3 Thr241Met polymorphism and oral cancer risk.

Life style Adjusted

First authors (Refs.) Genotypes OR 95\% CI P-value

No areca nut chewing

$\begin{array}{lllrl}\text { Kietthubthew } \text { et al }(10) & \mathrm{CT} / \mathrm{TT} & 2.61 & 0.97-7.11 & 0.06 \\ \text { Yang } \text { et al }(12) & \mathrm{CT} / \mathrm{TT} & 0.5 & 0.0-11.5 & \mathrm{~N} / \mathrm{A} \\ \text { Tsai } \text { et al }(16) & \mathrm{CT} / \mathrm{TT} & 1.1 & 0.56-2.17 & 0.86 \\ \text { Areca nut chewing } & & & & \\ \text { Kietthubthew } \text { et al }(10) & \mathrm{CT} / \mathrm{TT} & 2.85 & 0.72-11.3 & 0.14 \\ \text { Yang } \text { et al }(12) & \mathrm{CT} / \mathrm{TT} & 0.4 & 0.1-1.9 & \mathrm{~N} / \mathrm{A} \\ \text { Tsai } \text { et al }(16) & \mathrm{CT} / \mathrm{TT} & 1.94 & 1.31-2.87 & 0.001\end{array}$

N/A, not applicable. XRCC3, X-ray repair cross complementing group 3 .

Publication bias and sensitivity analysis. As there was substantial heterogeneity among studies during the process of comprehensive comparisons, sensitivity analyses were performed to indicate the effect of each single data against the aggregated ORs. The recalculated ORs are not substantially influenced, suggesting that our results are reliable and they verify the hardiness of the present investigation. The Egger's test and funnel plots were applied to validate potential bias from the published literature. Shape of the funnel plots is approximately symmetrical. Egger's test result shows no statistical evidence for bias $(P>0.05)$, indicating that there is no obvious bias in this meta-analysis based on the searched publications and the results are plausible (Fig. 6). 


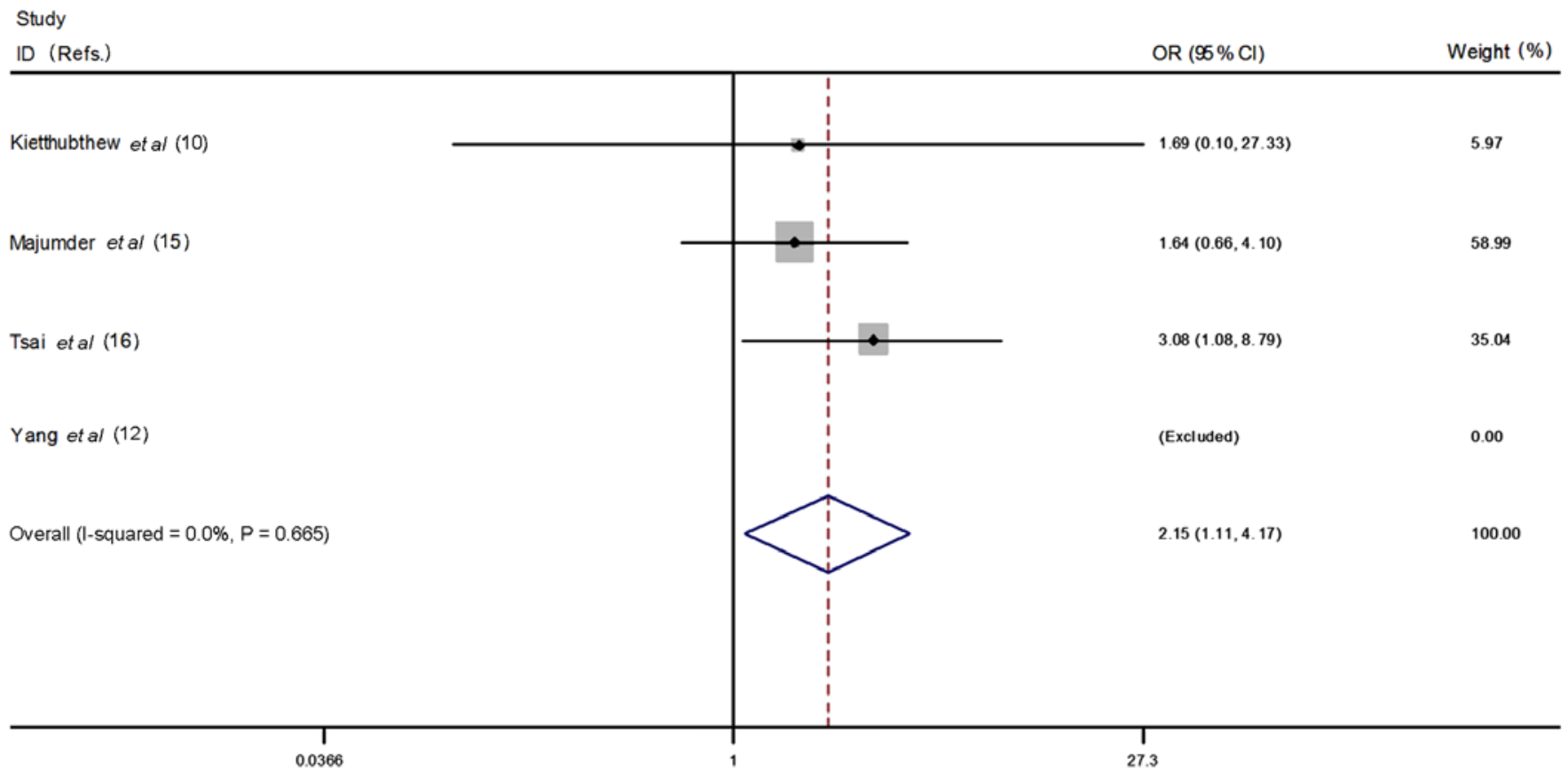

Figure 7. Stratification analysis of the correlation regarding XRCC3 Thr241Met polymorphism to oral cancer risk through the homozygous model (TT versus CC) in Asians. XRCC3, X-ray repair cross complementing group 3.

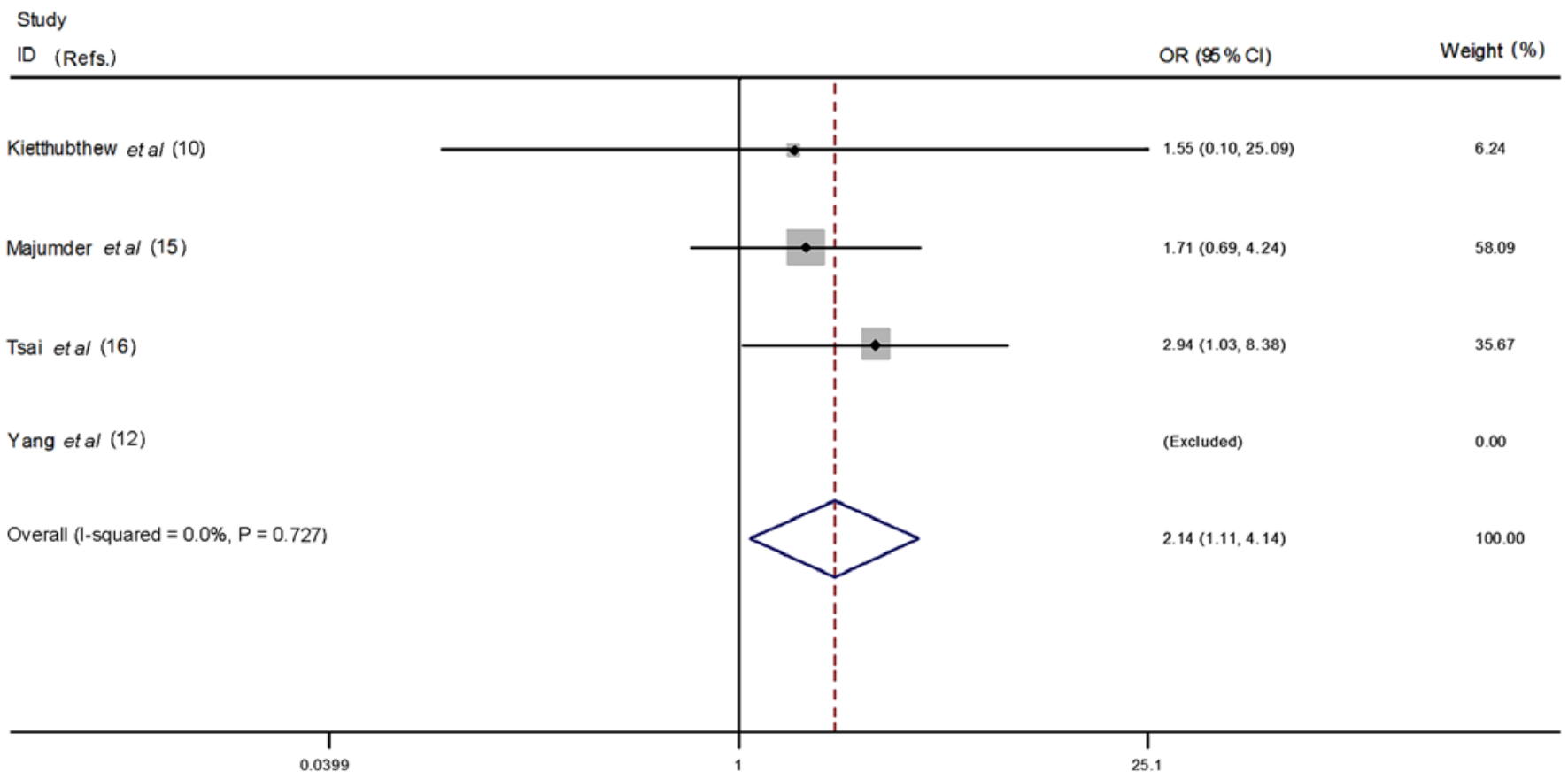

Figure 8. Stratification analysis of the correlation regarding XRCC3 Thr241Met polymorphism to oral cancer risk via the recessive model (TT versus CC + CT) in Asians. XRCC3, X-ray repair cross complementing group 3.

Stratified analyses by ethnicity and areca nut chewing. In the ethnicity stratified analysis, more significant associations were detected in Asian population. (Asians: homozygous model $\mathrm{CC}$ vs. TT: $\mathrm{OR}=2.15,95 \% \mathrm{CI}=1.11-4.17, \mathrm{P}=0.02$, heterogeneity $\mathrm{P}=0.67, \mathrm{I}^{2}=0.0 \%$, Fig. 7 ; recessive model $\mathrm{CT}+\mathrm{CC}$ vs. TT: $\mathrm{OR}=2.14,95 \% \mathrm{CI}=1.11-4.14, \mathrm{P}=0.02$, heterogeneity $\mathrm{P}=0.78$, $\mathrm{I}^{2}=0.0 \%$, Fig. 8; heterozygous model $\mathrm{CC}$ vs. $\mathrm{CT}$ : $\mathrm{OR}=1.20$, 95\% $\mathrm{CI}=0.80-1.81, \mathrm{P}=0.38$, heterogeneity $\mathrm{P}=0.04, \mathrm{I}^{2}=63.9 \%$; dominant model CC vs. TT + CT: $\mathrm{OR}=1.25, \mathrm{P}=0.29,95 \%$
$\mathrm{CI}=0.83-1.88$, heterogeneity $\mathrm{P}=0.03, \mathrm{I}^{2}=66.2 \%$; allele $\mathrm{C}$ vs. $\mathrm{T}$ : $\mathrm{OR}=1.28,95 \% \mathrm{CI}=0.87-1.88, \mathrm{P}=0.21$, heterogeneity $\mathrm{P}=0.03$, $\mathrm{I}^{2}=67.5 \%$ ). No significant association were identified in Caucasians: (homozygous model CC vs. TT: OR=1.09, 95\% $\mathrm{CI}=0.47-2.53, \mathrm{P}=0.84$, heterogeneity $\mathrm{P}=0.09, \mathrm{I}^{2}=57.7 \%$; recessive model $\mathrm{CT}+\mathrm{CC}$ vs. TT: $\mathrm{OR}=1.43,95 \% \mathrm{CI}=0.57-3.61$, $\mathrm{P}=0.45$, heterozygous model $\mathrm{CC}$ vs. $\mathrm{CT}$ : $\mathrm{OR}=0.75,95 \%$ $\mathrm{CI}=0.25-2.27, \mathrm{P}=0.61$, heterogeneity $\mathrm{P}=0.001, \mathrm{I}^{2}=87.1 \%$; dominant model $\mathrm{CC}$ vs. $\mathrm{TT}+\mathrm{CT}$ : $\mathrm{OR}=0.92, \mathrm{P}=0.82,95 \%$ 


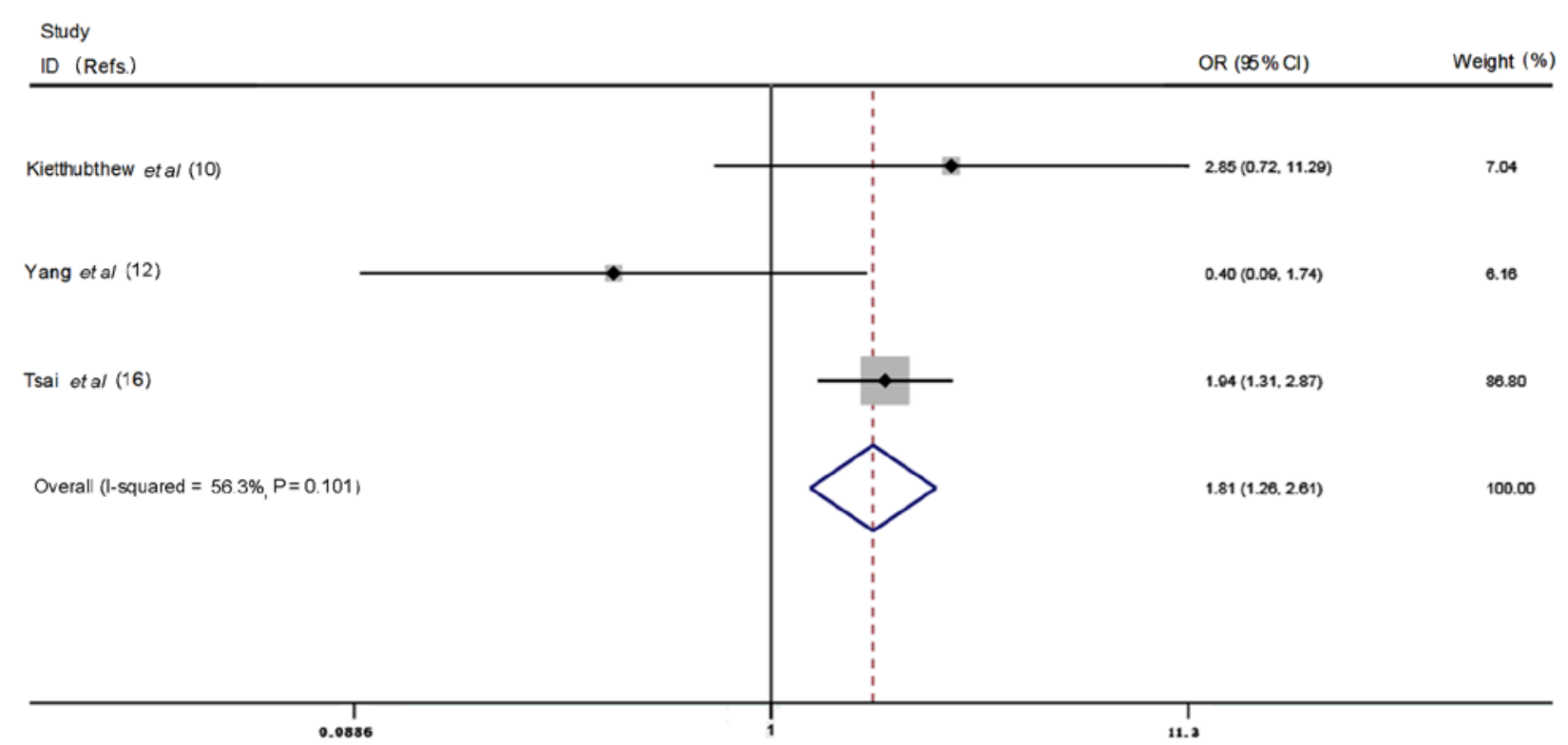

Figure 9. There is no significant association between the $\mathrm{T}$ allele carrier and oral cancer risk in people without areca nut chewing habit $(\mathrm{OR}=1.40,95 \%$ $\mathrm{CI}=0.81-2.43, \mathrm{P}=0.23$, heterogeneity $\left.\mathrm{P}=0.30, \mathrm{I}^{2}=16.9 \%\right)$. In the areca nut chewers, $\mathrm{T}$ allele carrier had significantly higher risk of oral cancer $(\mathrm{OR}=1.81,95 \%$ $\mathrm{CI}=1.26-2.61, \mathrm{P}=0.001$, heterogeneity $\mathrm{P}=0.10, \mathrm{I} 2=56.3 \%)$.

$\mathrm{CI}=0.92-1.95$, heterogeneity $\mathrm{P}=0.02, \mathrm{I}^{2}=66.2 \%$; heterogeneity $\mathrm{P}=0.03, \mathrm{I}^{2}=71.9 \%$; allele $\mathrm{C}$ vs. $\mathrm{T}: \mathrm{OR}=1.11,95 \% \mathrm{CI}=0.74-1.69$, $\mathrm{P}=0.61$, heterogeneity $\mathrm{P}=0.05, \mathrm{I}^{2}=66.4 \%$ ). Three studies included areca nut chewing for stratified analysis, which allowed for further analysis (Table II). There was no significant association between the $\mathrm{T}$ allele carrier and oral cancer risk in people without areca nut chewing habit $(\mathrm{OR}=1.40,95 \%$ $\mathrm{CI}=0.81-2.43, \mathrm{p}=0.23$, heterogeneity $\left.\mathrm{P}=0.30, \mathrm{I}^{2}=16.9 \%\right)$. In the areca nut chewers, $\mathrm{T}$ allele carrier had significantly higher risk of oral cancer $(\mathrm{OR}=1.81,95 \% \mathrm{CI}=1.26-2.61, \mathrm{P}=0.001$, heterogeneity $\mathrm{P}=0.10, \mathrm{I}^{2}=56.3 \%$, Fig. 9).

\section{Discussion}

DNA repairing systems play an indispensable role in protecting cells against carcinogenic agents. It is largely accepted that environmental carcinogens would stimulate DNA damage, which would then induct genomic instability (17). In this manner, alternations in DNA repairing genes may potentially influence the susceptibility of each disease, which would affect therapy as well as prognosis (18-20). In the current study, we verified the association between XRCC3 Thr241Met polymorphism and oral cancer risk. Results illustrated that TT (Met/Met) genotype was associated with high risk of oral cancer through the recessive model $(\mathrm{P}=0.001)$. Further stratification analyses demonstrated that the Met/Met genotype was significantly associated with oral cancer under both recessive and homozygous models in Asians $(\mathrm{P}<0.05)$. In contrast, no association was detected regarding XRCC3 Thr241Met polymorphisms to oral cancer risk in non-Asians.

$X R C C 3$, a paralog of RAD51 protein, functions in homologous recombination repair (HRR) pathway and maintaining genomic stability in mammalian cells. The Thr241Met polymorphism resides in an evolutionary conserved region, the adenosine triphosphate-binding domain, which is the exclusive region with certain functional activity of $X R C C 3$ protein (21). The Thr241Met polymorphism is suggested to have a possible mechanic function in the protein structure (22). For instance, XRCC3 241Met has been shown to be functionally deficient in repairing X-ray inducted chromosome aberrations, which infer that the genotyping of the variant is defective in the base excision repair (BER) (23). Several epidemiological studies have indicated that there was an association between $X R C C 3$ polymorphisms and oral cancer susceptibility, whereas a large amount of results remained contradictory. In the current study, the Met/Met genotype of Thr241Met polymorphism associated with high risk oral cancer was validated, which is consistent with previous functional studies. People with TT(Met/Met) genotype may have a defect in DNA repair function thus they are more susceptible to cancer, while those who have one and/or two Thr allele may have appropriate function which protects against cancer (23). People with homozygous of Met allele and defect in HRR function may be more susceptible to cancer, while those who have one and/or two Thr allele may have normal function which protects them against cancer. Moreover, by analysis of gene-environment interactions, comparison of the CC genotype demonstrated that the Met allele carriers had significantly increased risk of oral cancer in areca nut chewers, but not in those without this habit. As areca nut chewing may induce mitochondrial DNA mutation and oxidative DNA damage $(24,25)$, and people with the XRCC3 241Met allele and functional deficient in repair of DNA mutations may be susceptible to development of cancer. However, we were not able to perform further analysis with limited information regarding smoking, alcohol drinking and genotyping.

So far, there is only one meta-analysis report regarding the association of $X R C C 3 \mathrm{Thr} 241 \mathrm{Met}$ polymorphism to oral cancer risk reporting that $X R C C 3 \mathrm{Thr} 241 \mathrm{Met}$ polymorphism is irrelevant to the risk of oral cancer (26). However, the authors included upper aero-digestive cancer and leukoplakia, a common precancer lesion, in their association analysis. Biology 
may differ from tumors of different origins, for example, Benhamou et al (27) found that there is no significant association between the XRCC3 polymorphism and cancer of the upper aerodigestive tract. Analysis of widely determined cancer sites may lead to inconclusive results. In our analysis, more focused research on homogeneous cancer sites have reduced variations and are able to find a moderate association between XRCC3 Thr241Met polymorphism and oral cancer risk.

It is also important to note that the distributions of SNPs are highly different in various ethnic populations. Therefore, ethnicity may be a confounder. Previous association studies were performed in different populations, which may raise the discrepancy. For instance, the distribution of the XRCC3 Thr241Met variant genotypes (Thr/Met and Met/Met) was 14.0 and $0.6 \%$, respectively, in the Thai population (10). The distribution was 20.0 and $4.0 \%$, respectively, in Brazil population (11); 34.5 and $2.3 \%$ in Indian population (15); 54.7 and 26.4\% in Turkish population (14); 7.6 and $0.5 \%$ in Taiwan Chinese (16). From these results, it could be speculated that Chinese population may be more resistant to environmental carcinogens due to the fact that the population carry the Thr allele more frequently comparing with other populations. On the other hand, both Brazilian and Turkish populations are highly heterogeneous populations, with a mixture of European, Asian and African populations. In our study, stratification analysis illustrated that there was no significant association regarding XRCC3 Thr241Met polymorphism to oral cancer risk in these populations, indicating ethnic heterogeneity may affect the overall result of association studies.

Preliminary data show that the variant Met allele affects the development of oral cancer. The Met/Met genotype is also associated with at least 8 -fold increase of the risk for developing metastases. With respect to clinical diagnosis and practice, the Met/Met genotype was associated with a fairly high risk of developing oral cancer at either stage III or IV (11). In addition, the genotype of $X R C C 3 \mathrm{Thr} 241 \mathrm{Met}$ polymorphism was reported to be associated with tumor size (14). However, further studies using large populations are required to confirm these findings.

Finally, the potential of a polymorphism to impair DNA repair activity may be affected by other polymorphic alleles interfering in the process. For example, those nucleotide excision repairing genes for repair of smoking-induced DNA damage were not included in this study. We could not rule out a possibility that the Thr241Met polymorphism is within linkage disequilibrium regions with polymorphic genotype of other DNA repair genes. Therefore, further investigations exploring main contribution factors will be performed in the future to better understand the susceptibility phenomenon regarding oral cancer.

We suggest that the homozygote variants of Thr241Met polymorphism regarding XRCC 3 possibly act as factors for oral cancer risk. Moreover, the increased oral cancer risk was more obviously enhanced in Asians, but not in other populations. This study provides insight into whether DNA repair gene polymorphisms play an indispensable role in changing individual susceptibility to oral cancer. Further validations of gene-environment and gene-gene connections are necessary to explore the effects of XRCC3 Thr241Met polymorphisms on oral cancer.

\section{Acknowledgements}

We sincerely thank Mr. Jianxin Yang from the Second Affiliated Hospital of Soochow University (Suzhou, China), for his support with respect to the drafting of the manuscript.

\section{Funding}

This work was partly supported by funding of the China National Natural Science Foundation (no. 31100944) and the funding from Natural Science Foundation, Jiangsu Province, China (no. BK2009107).

\section{Availability of data and materials}

The data generated and/or analyzed in the present study are available from the corresponding author upon reasonable request.

\section{Authors' contributions}

JF drafted the manuscript. JF and WL performed quality assessment and data classification. MZ and CX conducted statistical analysis. All the authors have read and approved the final manuscript.

\section{Ethics approval and consent to participate}

The study was approved by the Ethics Committee of the Second Affiliated Hospital of Soochow University (Suzhou, China). Patients or their guardians signed an informed consent.

\section{Patient consent for publication}

Not applicable.

\section{Competing interests}

The authors declare that they have no competing interests.

\section{References}

1. Ferlay J, Soerjomataram I, Dikshit R, Eser S, Mathers C, Rebelo M, Parkin DM, Forman D and Bray F: Cancer incidence and mortality worldwide: Sources, methods and major patterns in GLOBOCAN 2012. Int J Cancer 136: E359-E386, 2015.

2. Chaturvedi AK, Anderson WF, Lortet-Tieulent J, Curado MP, Ferlay J, Franceschi S, Rosenberg PS, Bray F and Gillison ML: Worldwide trends in incidence rates for oral cavity and oropharyngeal cancers. J Clin Oncol 31: 4550-4559, 2013.

3. GBD 2013 Mortality and Causes of Death Collaborators: Global, regional, and national age-sex specific all-cause and cause-specific mortality for 240 causes of death, 1990-2013: A systematic analysis for the Global Burden of Disease Study 2013. Lancet 385: 117-171, 2015.

4. Chen MK, Chiou HL, Su SC, Chung TT, Tseng HC, Tsai HT and Yang SF: The association between hypoxia inducible factor1alpha gene polymorphisms and increased susceptibility to oral cancer. Oral Oncol 45: e222-e226, 2009.

5. Sugimura T, Kumimoto H, Tohnai I, Fukui T, Matsuo K, Tsurusako S, Mitsudo K, Ueda M, Tajima K and Ishizaki K: Gene-environment interaction involved in oral carcinogenesis: Molecular epidemiological study for metabolic and DNA repair gene polymorphisms. J Oral Pathol Med 35: 11-18, 2006.

6. Risch N and Merikangas K: The future of genetic studies of complex human diseases. Science 273: 1516-1517, 1996. 
7. Bănescu C, Tilinca M, Benedek EL, Demian S, Macarie I, Duicu C and Dobreanu M: XRCC3 Thr241Met polymorphism and risk of acute myeloid leukemia in a Romanian population. Gene 526: 478-483, 2013

8. Yang L, An Y, Wang G, Lu T and Yang S: Association between XRCC3 Thr241Met polymorphism and risk of osteosarcoma in a Chinese population. Int J Clin Exp Pathol 8: 11670-11674, 2015.

9. Michalska MM, Samulak D, Romanowicz H, Jabłoński F and Smolarz B: Association between single nucleotide polymorphisms (SNPs) of XRCC2 and XRCC3 homologous recombination repair genes and ovarian cancer in Polish women. Exp Mol Pathol 100: 243-247, 2016.

10. Kietthubthew S, Sriplung H, Au WW and Ishida T: Polymorphism in DNA repair genes and oral squamous cell carcinoma in Thailand. Int J Hyg Environ Health 209: 21-29, 2006.

11. dos Santos Pereira J, Fontes FL, de Medeiros SR de Almeida Freitas R, de Souza LB and da Costa Miguel MC: Association of the XPD and XRCC3 gene polymorphisms with oral squamous cell carcinoma in a Northeastern Brazilian population: A pilot study. Arch Oral Biol 64: 19-23, 2016.

12. Yang $\mathrm{CH}$, Lin YD, Yen CY, Chuang LY and Chang HW: A systematic gene-gene and gene-environment interaction analysis of DNA repair genes XRCC1, XRCC2, XRCC3, XRCC4, and oral cancer risk. OMICS 19: 238-247, 2015.

13. Dos Reis MB,Losi-Guembarovski R, de Souza Fonseca RibeiroEM, Cavalli IJ, Morita MC, Ramos GH, de Oliveira BV, Mizuno LT, Rogatto SR and de Syllos Cólus IM: Allelic variants of XRCC1 and XRCC3 repair genes and susceptibility of oral cancer in Brazilian patients. J Oral Pathol Med 42: 180-185, 2013.

14. Avci H, Ergen A, Bireller ES, Ertugrul B and Cakmakoglu B: A strong relationship between oral squamous cell carcinoma and DNA repair genes. Biochem Genet 55: 378-386, 2017.

15. Majumder M, Sikdar N, Paul RR and Roy B: Increased risk of oral leukoplakia and cancer among mixed tobacco users carrying $\mathrm{XRCC1}$ variant haplotypes and cancer among smokers carrying two risk genotypes: One on each of two loci, GSTM3 and XRCC1 (Codon 280). Cancer Epidemiol Biomarkers Prev 14: 2106-2112, 2005.

16. Tsai CW, Chang WS, Liu JC, Tsai MH, Lin CC and Bau DT: Contribution of DNA double-strand break repair gene XRCC3 genotypes to oral cancer susceptibility in Taiwan. Anticancer Res 34: 2951-2956, 2014.

17. Leemans CR, Braakhuis BJ and Brakenhoff RH: The molecular biology of head and neck cancer. Nat Rev Cancer 11: 9-22, 2011.

18. Werbrouck J, De Ruyck K, Duprez F, Veldeman L, Claes K, Van Eijkeren M, Boterberg T, Willems P, Vral A, De Neve W, et al: Acute normal tissue reactions in head-and-neck cancer patients treated with IMRT: Influence of dose and association with genetic polymorphisms in DNA DSB repair genes. Int J Radiat Oncol Biol Phys 73: 1187-1195, 2009.
19. da Silva BS, Rovaris DL, Bonotto RM, Meyer JB, Grohe RE, Perassolo MS, Palazzo RP, Maluf SW, Linden R and de Andrade FM: The influence on DNA damage of glycaemic parameters, oral antidiabetic drugs and polymorphisms of genes involved in the DNA repair system. Mutagenesis 28: 525-530, 2013.

20. Chang WS, Tsai CW, Wang JY, Ying TH, Hsiao TS, Chuang CL, Yueh TC, Liao CH, Hsu CM, Liu SP, et al: Contribution of $\mathrm{X}$-ray repair complementing defective repair in Chinese hamster cells 3 (XRCC3) genotype to leiomyoma risk. Anticancer Res 35: 4691-4696, 2015.

21. Manuguerra M, Saletta F, Karagas MR, Berwick M, Veglia F, Vineis P and Matullo G: XRCC3 and XPD/ERCC2 single nucleotide polymorphisms and the risk of cancer: A HuGE review. Am J Epidemiol 164: 297-302, 2006.

22. Werbrouck J, De Ruyck K, Duprez F, Van Eijkeren M, Rietzschel E, Bekaert S, Vral A, De Neve W and Thierens H: Single-nucleotide polymorphisms in DNA double-strand break repair genes: Association with head and neck cancer and interaction with tobacco use and alcohol consumption. Mutat Res 656: 74-81, 2008.

23. $\mathrm{Au} \mathrm{WW}$, Salama SA and Sierra-Torres CH: Functional characterization of polymorphisms in DNA repair genes using cytogenetic challenge assays. Environ Health Perspect 111: 1843-1850, 2003.

24. Tan DJ, Chang J, Chen WL, Agress LJ, Yeh KT, Wang B and Wong LJ: Novel heteroplasmic frameshift and missense somatic mitochondrial DNA mutations in oral cancer of betel quid chewers. Genes Chromosomes Cancer 37: 186-194, 2003.

25. Chen CL, Chi CW and Liu TY: Hydroxyl radical formation and oxidative DNA damage induced by areca quid in vivo. J Toxicol Environ Health A 65: 327-336, 2002.

26. Zhang EJ, Cui ZG, Xu ZF, Duan WY, Huang SH, Tan XX, Yin ZH, Sun CF and Lu L: Lack of influence of an XRCC3 gene polymorphism on oral cancer susceptibility: Meta-analysis. Asian Pac J Cancer Prev 15: 10329-10334, 2014.

27. Benhamou S, Tuimala J, Bouchardy C, Dayer P, Sarasin A and Hirvonen A: DNA repair gene XRCC2 and XRCC3 polymorphisms and susceptibility to cancers of the upper aerodigestive tract. Int J Cancer 112: 901-904, 2004.

This work is licensed under a Creative Commons Attribution-NonCommercial-NoDerivatives 4.0 International (CC BY-NC-ND 4.0) License. 